\title{
BMP4 induces asymmetric cell division in human glioma stem-like cells
}

\author{
MOTOFUMI KOGUCHI ${ }^{1}$, YUKIKO NAKAHARA ${ }^{1}$, HIROSHI ITO ${ }^{1}$, \\ TOMIHIRO WAKAMIYA ${ }^{1}$, FUMITAKA YOSHIOKA ${ }^{1}$, ATSUSHI OGATA $^{1}$, \\ KOHEI INOUE $^{1}$, JUN MASUOKA ${ }^{1}$, HIDEKI IZUMI $^{2 *}$ and TATSUYA ABE ${ }^{1 *}$ \\ ${ }^{1}$ Department of Neurosurgery, Faculty of Medicine, Saga University, Saga 849-8501; ${ }^{2}$ Laboratory of Molecular Medicine, \\ Life Sciences Institute, Saga Medical Center KOSEIKAN, Saga 840-8571, Japan
}

Received June 25, 2019; Accepted November 25, 2019

DOI: $10.3892 / \mathrm{ol} .2019 .11231$

\begin{abstract}
Glioblastoma (GBM) is a malignant tumor with a high recurrence rate and has very poor prognosis in humans. The median survival is still $<2$ years. Therefore, a new treatment strategy should be established. Recently, this cancer has been thought to be heterogeneous, consisting of cancer stem cells (CSCs) that are self-renewable, multipotent, and treatment resistant. So various strategies targeting glioma stem-like cells (GSCs) have been investigated. This study focused on strategies targeting GSCs through the induction of differentiation using bone morphogenetic protein 4 (BMP4). The expression of CD133, a cancer stem cell marker, under BMP4 treatment in GSCs was examined using flow cytometry, western blotting, and quantitative PCR. Immunofluorescent staining of GSCs was also performed to examine the type of cell division: asymmetric cell division (ACD) or symmetric cell division (SCD). We obtained the following results. The BMP4 treatment caused downregulation of CD133 expression. Moreover, it induced ACD in GSCs. While the ACD ratio was $23 \%$ without BMP4 treatment, it was $38 \%$ with BMP4 treatment $(\mathrm{P}=0.004)$. Furthermore, the tumor sphere assay demonstrated that BMP4 suppresses self-renewal ability. In conclusion, these findings may provide a new perspective on how BMP4 treatment reduces the tumorigenicity of GSCs.
\end{abstract}

\section{Introduction}

Glioblastoma (GBM) is one of the malignant tumors with high recurrence rate and worst prognosis in humans $(1,2)$.

Correspondence to: Dr Hideki Izumi, Laboratory of Molecular Medicine, Life Sciences Institute, Saga Medical Center KOSEIKAN, Training Building 3F, 400 Nakabura, Kase, Saga 840-8571, Japan

E-mail: izumi-hideki@koseikan.jp

*Contributed equally

Key words: cell differentiation, asymmetric cell division, AC133, neoplastic stem cell, glioblastoma
As the mechanism of its development and invasion remains poorly understood, its treatment regimens are still limited. The median survival is $<2$ years, although the best optimal treatment has been provided $(1,2)$. Thus, a new treatment strategy should be established. GBM is associated with a variety of genetic and epigenetic changes, and these risk factors induce tumor development and progression. Based on this, various therapeutic strategies such as epigenetic drugs, micro-RNAs, and gene editing are considered $(3,4)$.

Recently, cancer has been thought to be heterogeneous, comprising cancer stem cells (CSCs) with self-renewal ability and multipotency. CSCs produce cancer cells with differentiated potential $(5,6)$. The heterogeneity of cancer has been known to be associated with resistance to chemotherapy and radiotherapy. The treatment strategies for CSCs, which are involved in treatment resistance, are attracting attention (7). Previous studies showed that cells corresponding to CSCs also exist in GBM (8-10). Therefore, to realize the long-term survival and GBM treatment, the development of therapies targeting glioma stem-like cells (GSCs) has been considered important $(11,12)$. Various strategies targeting GSCs have been investigated (13-15), including those targeting the vascular niche in GSCs $(13,16)$; specific cell surface molecules in GSCs, such as CD133 $(9,17)$ and L1CAM (18); and specific signaling pathways in GSCs, such as RTK-Akt (19-21) and Notch signaling (22). This study focused on strategies targeting GSCs through the induction of differentiation, which is different from those in a previous study. Bone morphogenetic protein 4 (BMP4) is one of the most important factors in cell dynamics. BMP is a member of the transforming growth factor beta (TGF- $\beta$ ) family and plays a very important role in regulating cell proliferation, differentiation, and development in various biological systems (23-27). Interestingly, evidences that BMP4 can promote differentiation of GBM cells have been increasing (28-31). Moreover, dysfunction of the BMP pathway in GSCs has also been reported (28-31). Furthermore, BMP4 has been reported to inhibit the tumorigenic potential through GSC differentiation as well as proliferation suppression (31).

CSCs balance self-renewal ability and multipotency in order to adapt to various environments. CSCs divide into two daughter cells using one of the two types of cell division: asymmetric cell division (ACD) or symmetric cell 
division (SCD) $(32,33)$. With ACD, one CSC divides into one differentiated cell and one self-renewing stem cell, whereas with SCD, one CSC divides into two equal CSCs. SCD is advantageous for CSC expansion in the tumor tissue. The concept termed 'ACD therapy' suppresses CSC symmetric cell division (self-renewal ability) and inhibits CSC expansion. Thus, 'ACD therapy' may be established as a new strategy for the treatment of cancer.

The present study aimed to examine GSCs' cell division pattern under BMP4 treatment. Herein, we present the evidence that BMP4 induces GSCs' ACD by inhibiting its self-renewal ability.

\section{Materials and methods}

Cell culture. Patient-derived GSC MGG8 was obtained from Massachusetts General Hospital as previously described (34). Cells were maintained in the stem cell culture medium [Neurobasal medium (Gibco; Invitrogen), supplemented with $3 \mathrm{mM}$ of L-glutamine (Cellgro), B27 supplement (Gibco; Invitrogen), N2 supplement (Gibco; Invitrogen), heparin (Sigma), penicillin/streptomycin/amphotericin B (Cellgro), human recombinant FGF-2 (Peprotech) for final $20 \mathrm{ng} / \mathrm{ml}$, human recombinant EGF (R and D systems) for final $20 \mathrm{ng} / \mathrm{ml}$. Furthermore, cells were cultured in an atmosphere containing $5 \% \mathrm{CO}_{2}$ at $37^{\circ} \mathrm{C}$. Recombinant human bone BMP-4 was purchased from R\&D Systems.

Antibodies. Primary antibodies used were as follows: AntiCD133 (W6B3C1) [1:10 for immunofluorescence (IF), 1:100 for immunoblotting (WB), 130-092-395, Miltenyi Biotec], anti-Smad1 (1:1,000 for WB, cat. no. 9743; Cell Signaling Technology), anti-phospho-Smad1/5/9 (1:1,000 for WB, cat. no. 13820; Cell Signaling Technology), anti-Smad4 (1:1,000 for WB, 1:500 for IF, cat. no. 46535; Cell Signaling Technology), anti-PCNA (1:1,000 for WB, NB100-456; Novus Biologicals), anti-tubulin (1:1,000 for WB, T5326; Sigma-Aldrich), antiGAPDH (1:1,000 for WB, 60004-1-Ig; Proteintech), and anti-MKLP-1 (1:100 for IF, sc-867; Santa Cruz Biotechnology). Horseradish peroxidase-labeled secondary antibodies were purchased from the General Electric (GE) Healthcare and used at 1:10,000. Fluorescence-labeled Alexa secondary antibodies used in this study were obtained from Molecular Probes and used at 1:500.

Flow cytometry. Cell surface antigen expressions were analyzed using flow cytometry. CD133/1-PE (Miltenyi Biotec) and mouse IgG1-PE isotype control antibody (Miltenyi Biotec) were used according to manufacturer's instructions. MGG8 was incubated with these antibodies for $10 \mathrm{~min}$ at $4^{\circ} \mathrm{C}$ and then washed and analyzed using a MACSQuant Analyzer (Miltenyi Biotec).

$R N A$ extraction and reverse transcription-quantitative $P C R$ $(q P C R)$. The total RNA was extracted using RNeasy Mini kit from Qiagen according to the manufacturer's instructions. RNA was reverse transcribed using the Omniscript Reverse Transcription kit (Qiagen). The following primer sequences were used for PCR: CD133 (PROM1) sense 5'-agtggcatcgtgcaaacgata-3' and antisense 5'-ctccgaatccattcgacgata-3' and
GAPDH (internal control) sense 5'-gcaccgtcaaggctgagaac-3' and antisense 5'-tggtgaagacgccagtgga-3'. The qPCR reactions were performed on the Step One Plus (Applied Biosystems) using the Power Up SYBR Green Master Mix (Applied Biosystems). Cycling conditions were initial denaturation at $95^{\circ} \mathrm{C}$ for $10 \mathrm{~min}$, then 40 cycles at $95^{\circ} \mathrm{C}$ for $15 \mathrm{sec}$ and $60^{\circ} \mathrm{C}$ for $1 \mathrm{~min}$.

Immunoblotting. Cells were lysed in the SDS/Nonidet P-40 lysis buffer [1\% SDS, 1\% Nonidet P-40, $50 \mathrm{mM}$ Tris (pH 8.0), $150 \mathrm{mM} \mathrm{NaCl}, 2 \mu \mathrm{g} / \mathrm{ml}$ leupeptin, $2 \mu \mathrm{g} / \mathrm{ml}$ aprotinin, $1 \mathrm{mM}$ phenylmethylsulfonyl fluoride (PMSF), $5 \mathrm{mM} \mathrm{NaF}$, and $\left.100 \mu \mathrm{M} \mathrm{Na} \mathrm{VO}_{4}\right]$. Nucleus and cytosol protein fractions were extracted using Nuclear/Cytosol Fractionation kit (BioVision). The lysates were boiled for $5 \mathrm{~min}$ and then cleared by centrifugation at 15,000 rpm and $4^{\circ} \mathrm{C}$. A Bradford protein assay reagent (BioRad) was used to determine the protein concentration of supernatants. Lysates were further boiled for $5 \mathrm{~min}$ in the sample buffer. Then, samples were resolved using the SDS-PAGE and transferred onto Immobilon-P (Millipore Corp.) sheets. Blots were first incubated in blocking buffer [5\% (w/v) nonfat dry milk in Tris-buffered saline (TBS) plus $0.05 \%$ Tween 20] for $30 \mathrm{~min}$. Then, they were incubated with a primary antibody for $16 \mathrm{~h}$ at $4^{\circ} \mathrm{C}$, followed by incubation with a horseradish peroxidase-conjugated secondary antibody for $30 \mathrm{~min}$ at room temperature (RT). The ECL-plus chemiluminescence (GE Healthcare) was used to visualize antibody-antigen complex.

Indirect immunofluorescence and cell imaging. Cells grown on coverslips were briefly washed with phosphate-buffered saline (PBS) three times, and then fixed with $4 \%$ paraformaldehyde for $15 \mathrm{~min}$ at RT or ice cold methanol for $20 \mathrm{~min}$ at $-20^{\circ} \mathrm{C}$. A $1 \%$ NP-40 in PBS solution was used to treat the cells for $10 \mathrm{~min}$, which were incubated with blocking solution (15\% bovine serum albumin in PBS) for $1 \mathrm{~h}$. The cells were then probed with primary antibodies for $1 \mathrm{~h}$ at $37^{\circ} \mathrm{C}$, and antibody-antigen complexes were detected with either Alexa Fluor 594- or Alexa Fluor 488-conjugated donkey secondary antibody by incubation for $1 \mathrm{~h}$ at RT. The samples were washed three times with TBS after each incubation and then counterstained with 4',6'-diamidino-2-phenylindole. Immunostained cells were examined under a fluorescence microscope (Olympus IX73, Tokyo, Japan) using a 100x or 60x objective lens. Fluorescence images were captured using a CCD camera (Olympus, DP27) and processed with Adobe Photoshop CC and ImageJ.

Mitotic analysis. TrypLE Express (Thermo Fisher) was used to separate sphere-cultured cells. Mitotic cells were collected by settling onto poly-L-lysine-coated coverslips at the bottom of 6-well plates using a centrifugation at 1,200 rpm. for $5 \mathrm{~min}$ at RT. For immunofluorescence analysis, cells were fixed, blocked, and stained as described. Cells in the late telophase (cytokinesis) were counted. ImageJ was used to measure the fluorescence intensity of a given staining for the two dividing daughter cells. For these values, the asymmetry cutoff was set with $>25 \%$ difference between the daughter cells (35). Values from these three independent experiments were summarized using frequencies and percentiles. 
A

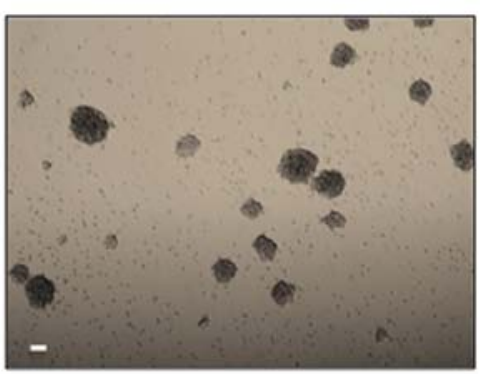

D

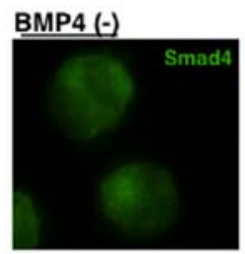

BMP4 (+)

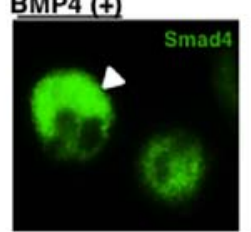

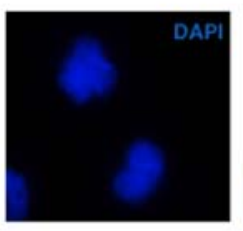

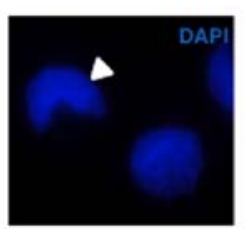

B

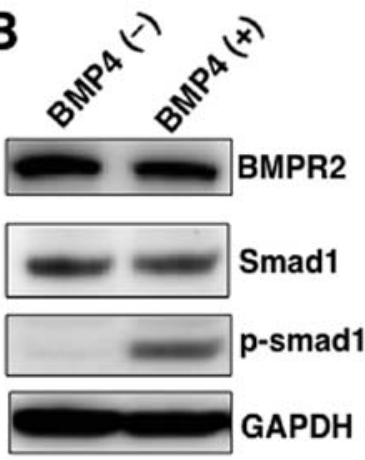

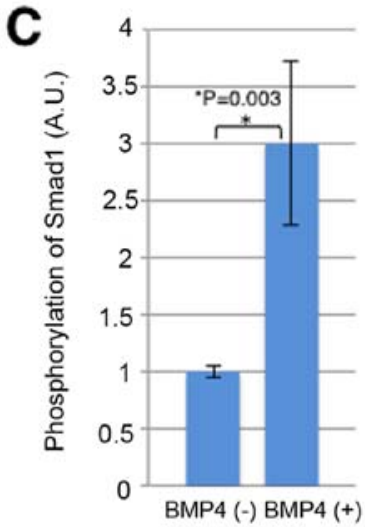

E
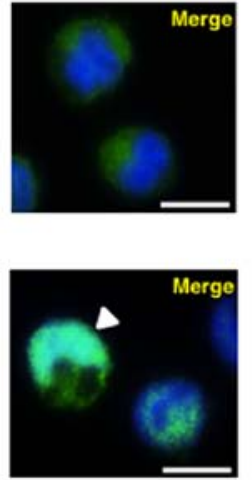
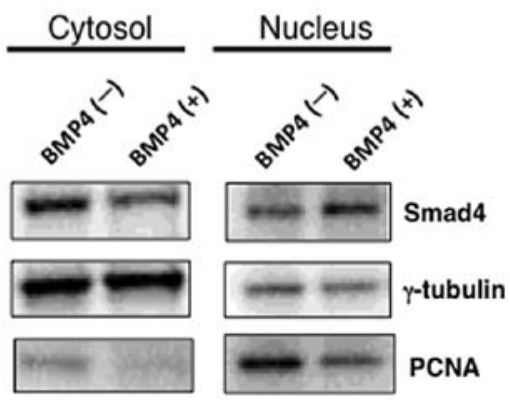

Figure 1. Smad signaling pathway is activated in the presence of BMP4 in MGG8 cells. (A) MGG8 spheres in the stem cell culture medium are presented. Scale bar, $100 \mu \mathrm{m}$. (B) Immunoblot analysis of Smad1 and phospho-Smad1 in MGG8 cells with or without BMP4 treatment. Immunoblot analysis of GAPDH as a loading control. (C) Quantitative expression analysis of p-Smad1 in MGG8 cells with or without BMP4 treatment. (D) Representative immunostaining images of Smad4 in MGG8 cells with or without BMP4 treatment. Smad4 is green and DAPI (DNA) is blue. Arrowheads show the nuclear localization of Smad4. Scale bar, $10 \mu \mathrm{m}$. (E) Immunoblot analysis of Smad4. Immunoblot analysis of tubulin (cytosol) and PCNA (nucleus) as a loading control. A total of two subcellular protein fractions (cytosol and nucleus fractions) were extracted from MGG8 cells with or without BMP4 treatment (100 ng/ml for 3 days). p, phosphorylated; BMP4, bone morphogenetic protein 4; PCNA, proliferating cell nuclear antigen.

Sphere formation assay. Sphere-cultured MGG8 cells were suspended in the stem cell culture medium at a density of $2.5 \times 10^{3}$ cells $/ \mathrm{ml}$, and $400 \mu \mathrm{l}$ of the cell suspension were transferred to each well in a non-coated 96-well plate. The spheres were counted after 3 days. Then, a hemocytometer was used to determine the cell number, and the dye exclusion method ( $0.1 \%$ trypan blue) was used determine the viability. MGG8 spheres of $>50 \mu \mathrm{m}$ were counted. Values from three independent experiments were summarized.

Statistical analysis. All statistical analyzes were performed using the JMP Pro. The unpaired Student's t test was used to compare the experimental groups, owing to the binary nature of data sets. $\mathrm{P}<0.05$ was considered to indicate a statistically significant difference. Data are presented as the mean \pm SEM.

\section{Results}

MGG8 cells responses in the BMP4-Smads pathway. First, MGG8 cells were confirmed to stably perform the sphereforming activity under GBM cancer stem-like cell-specific tissue culture conditions (Fig. 1A). MGG8 cells successfully continued showing cell proliferation by forming tumor spheres. When BMP4 binds to the BMP receptor, Smad1/5/8 are phosphorylated. Furthermore, the phosphorylated Smad1/5/8 forms a complex with Smad4 and then transmits a signal into the nucleus. The activated Smads regulate various biological effects, such as tissue homeostasis in cooperation with transcription factors, and perform transcriptional control for a specific cell state (23). Western blotting showed Smad1 phosphorylation under BMP4 treatment in MGG8 cells (Fig. 1B and C). Then, to confirm that Smads complex were transmitting signals into the nucleus, an immunofluorescence stained experiment for Smad4 was performed. As expected, Smad4 was localized into the nucleus under the BMP4 treatment (Fig. 1D). Futhermore, the western blotting of Smad4 in nucleus and cytosol fractions showed that Smad4 in the nuclear fraction increases under BMP4 treatment in MGG8 cells (Fig. 1E). These findings indicate that MGG8 cells may respond to BMP4-Smads pathway, the main pathway of BMP signaling.

BMP4 causes downregulation of CD133 expression in MGG8 cells. Sphere-cultured MGG8 cells were treated with BMP4 for $72 \mathrm{~h}$. Then, the CD133 expression was considered as stemness indicator $(36,37)$. Flow cytometry analysis showed that MGG8 cells expressed CD133 antigens and that BMP4 treatment resulted in a cell population with low expression levels of CD133 antigen (Fig. 2A). Real-time PCR was performed 

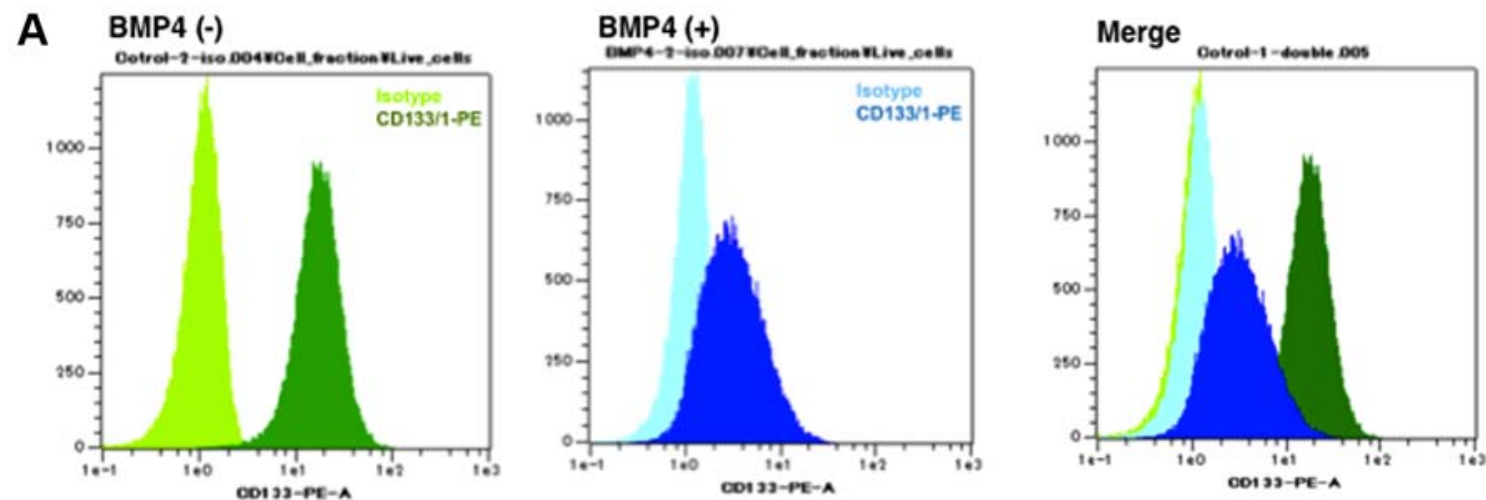

B

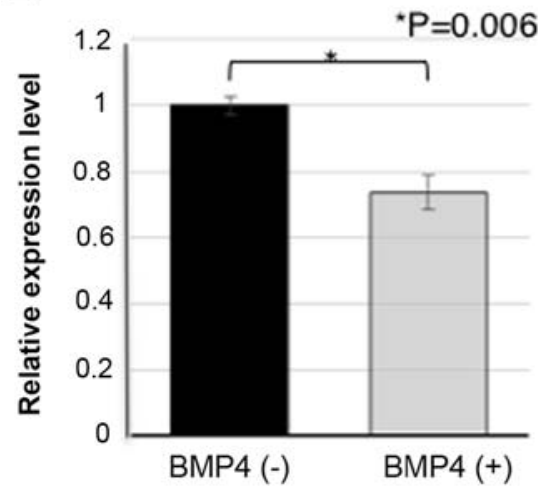

C

BMP4:

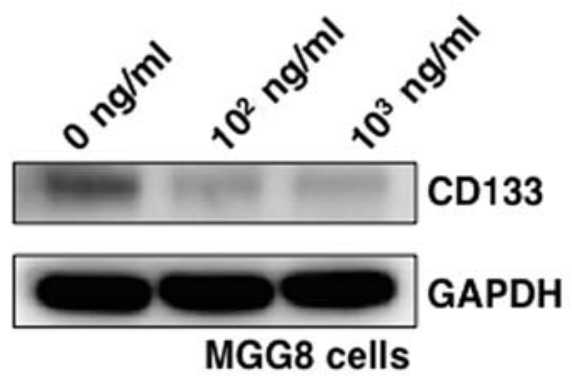

MGG8 cells

Figure 2. BMP4 treatment causes downregulation of CD133 expression in MGG8 cells. (A) Flow cytometry analysis of CD133 expression in MGG8 cells with or without BMP4 treatment (100 ng/ml for 3 days). Light green and light blue are the IgG1-PE isotype control. Green and blue are CD133-PE. (B) Quantitative PCR analysis of CD133 mRNA expression in MGG8 cells with or without BMP4 treatment (100 ng/ml for 3 days). Data are presented as the mean \pm SEM from three experiments. "P=0.006. (C) Immunoblot analysis of CD133 in MGG8 cells with or without BMP4 treatment (100 and 1,000 ng/ml for 3 days). Immunoblot of GAPDH as a loading control. BMP4, bone morphogenetic protein 4; PE, phycoerythrin.

\section{Telophase}
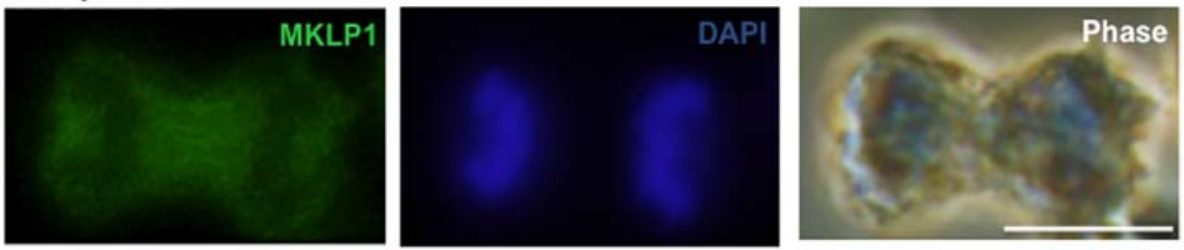

Late telophase/cytokinesis
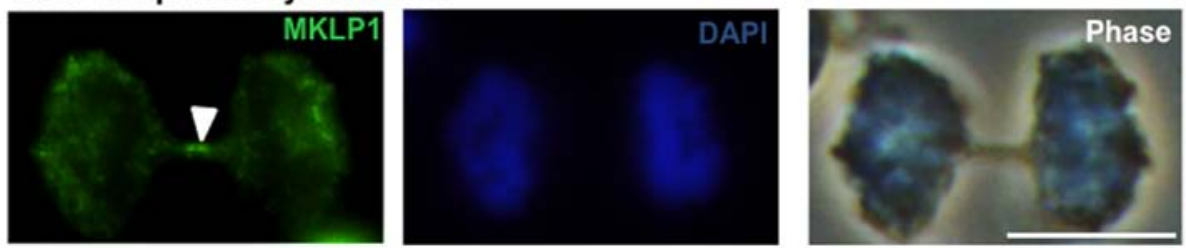

Figure 3. Representative immunostaining images in MGG8 cells during telophase and late telophase/cytokinesis. MKLP1 is green and DAPI (DNA) is blue. Phase-contrast images are also presented (right). MKLP1 (arrowhead) shows the Fleming body in the late telophase/cytokinesis. Scale bar, $10 \mu \mathrm{m}$. MKLP1, mitotic kinesin-like protein 1.

as quantitative gene expression analysis. As a result, the gene expression of CD133 was reduced in MGG8 cells under BMP4 treatment ( $\mathrm{P}=0.006$; Fig. 2B). Furthermore, western blotting was used to examine the expression levels of CD133 protein. BMP4 treatment caused CD133 protein downregulation in MGG8 cells. Therefore, upon BMP4 exposure, CD133 expression in MGG8 cells was reduced (Fig. 2C). These findings indicate that BMP4 exposure causes downregulation of CD133 expression in MGG8 cells.

Mitotic image analysis. Mitotic kinesin-like protein 1 (MKLP1) is specifically accumulated at the central part of 
A Symmetric cell division
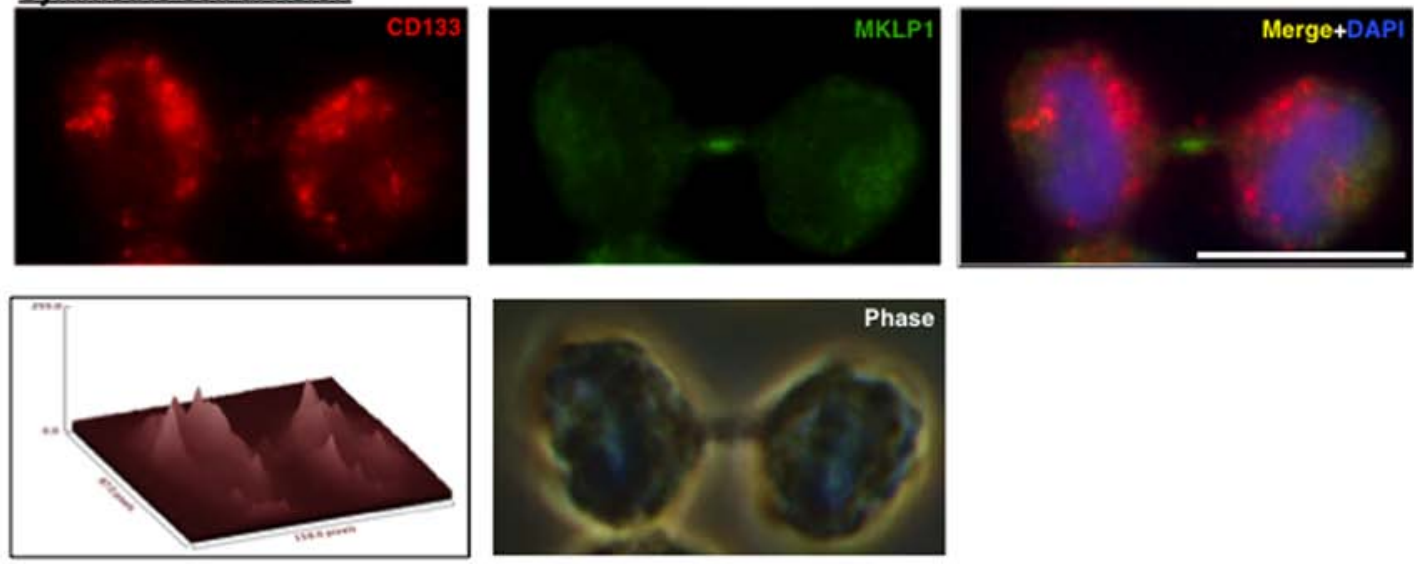

\section{Asymmetric cell division}
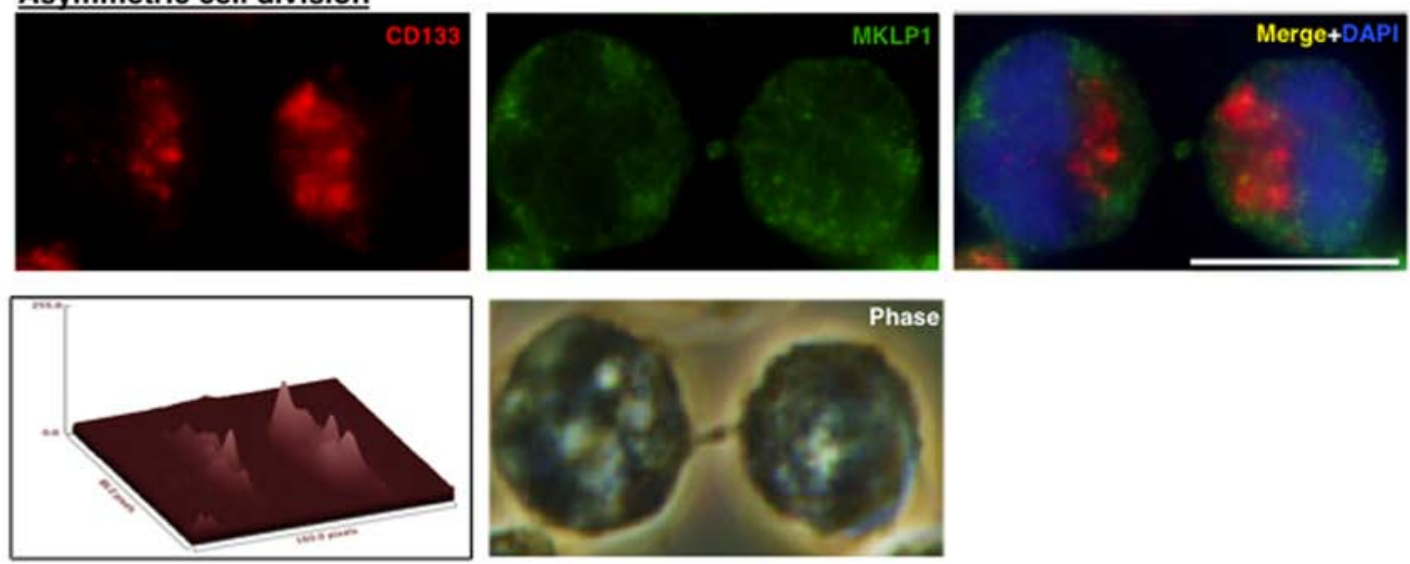

B

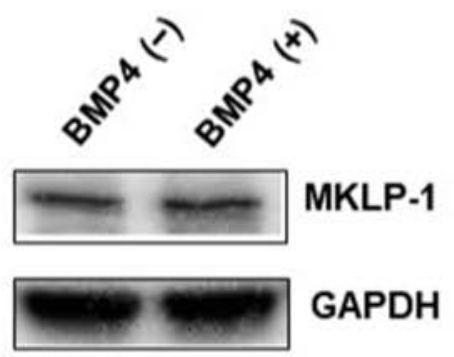

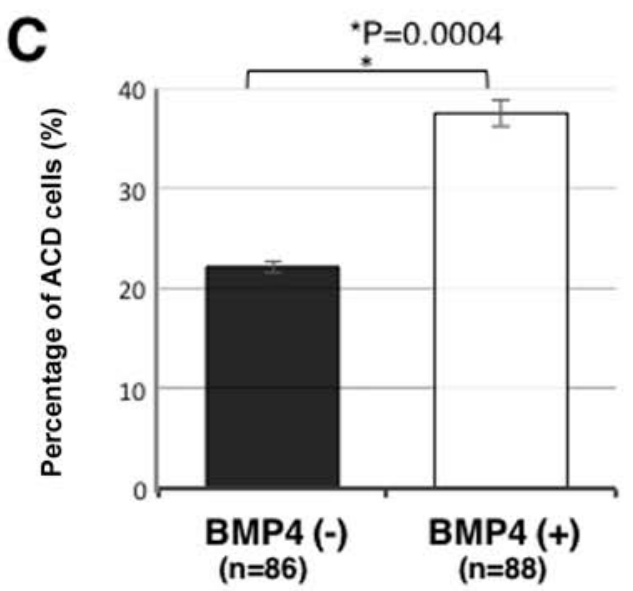

Figure 4. CD133-based ACD were induced by BMP4 in MGG8 cells. (A) Representative immunostaining images in the ACD and symmetric cell division in MGG8 cells. CD133 is red, MKLP1 is green, and DAPI (DNA) is blue. Merged and phase-contrast images are also presented. The signal intensity of CD133 in each daughter cell is also shown as a three-dimensional figure. Scale bar, $10 \mu \mathrm{m}$. (B) Immunoblot analysis of MKLP1 in MGG8 cells with or without BMP4 treatment. Immunoblot analysis of GAPDH as a loading control. (C) Quantification of cells using the ACD in MGG8 cells with or without BMP4 treatment. Data are presented as the mean \pm SEM from three experiments. ${ }^{*} \mathrm{P}=0.0004$. BMP4 treatment consisted of $100 \mathrm{ng} / \mathrm{ml}$ for 3 days. MKLP1, mitotic kinesin-like protein 1; ACD, asymmetric cell divisions; BMP4, bone morphogenetic protein 4.

microtubules (Fleming body) in the late telophase/cytokinesis (38). Therefore, an immunostaining experiment was performed using an anti-MKLP1 antibody (green fluorescence) in MGG8 cells. In the early telophase, no specific MKLP1 accumulation was observed. However, in its later stage, MKLP1 was specifically accumulated at the midbody, known as a Fleming body (Fig. 3). Therefore, MKLP1 immunostaining was used as a cytokinesis marker for further evaluation.

CD133-based ACDs induced by BMP4 in MGG8 cells. Next, whether BMP4 treatment induces ACD in MGG8 cells was examined. Representative immunostaining images in ACD and symmetric cell division in MGG8 cells are shown in 
A
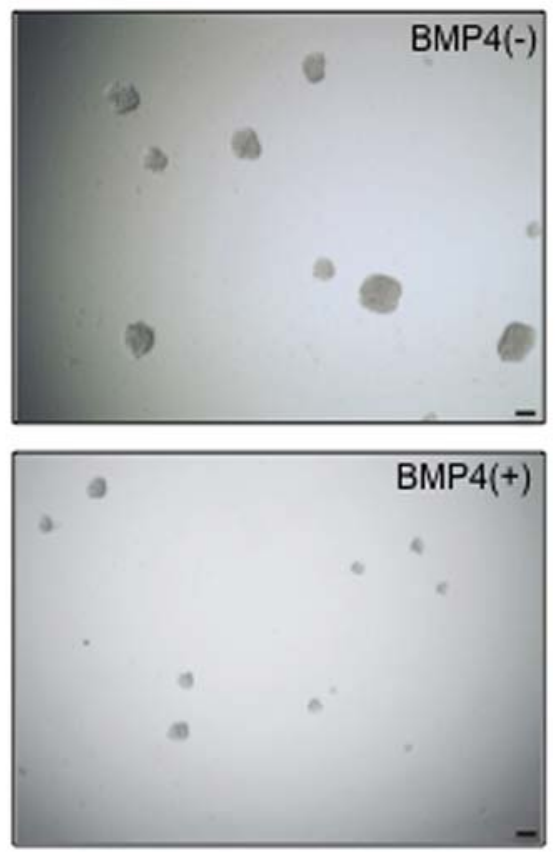

B

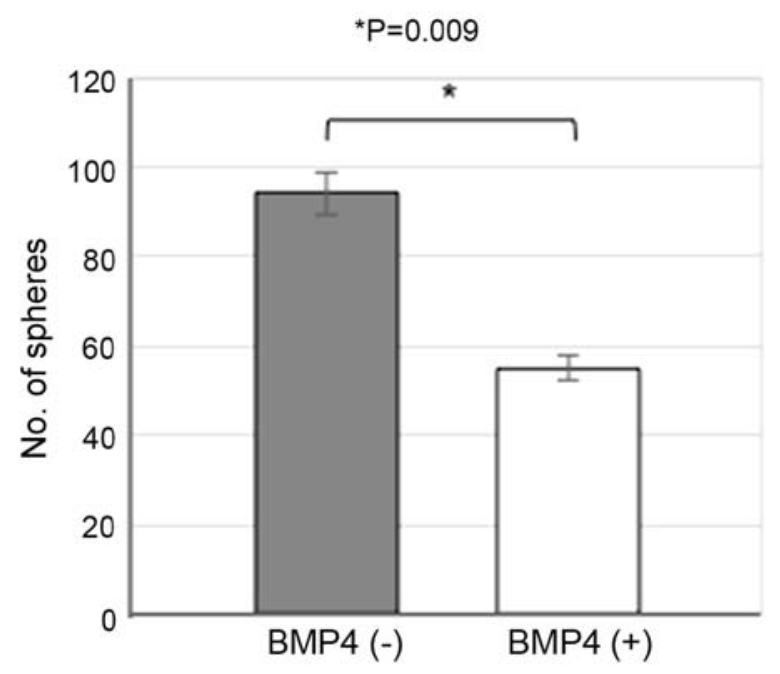

Figure 5. Sphere formation assay in MGG8 cells with or without BMP4 treatment. (A) MGG8 cells were cultured in the absence or presence of BMP4 (100 ng/ml for 3 days). MGG8 spheres cultured under each condition were shown. Scale bar, $100 \mu \mathrm{m}$. (B) Quantification of the number of spheres. MGG8 spheres of $>50 \mu \mathrm{m}$ diameter were counted. The number of spheres is indicated by ' $\mathrm{n}=94$ [BMP4 (-)]' and ' $\mathrm{n}=55$ [BMP4 (+)]'. Data are presented as the mean \pm SEM from three experiments. $\mathrm{P}=0.0009$. BMP4, bone morphogenetic protein 4 .

Fig. 4A. The asymmetry cutoff ratio was set as $>25 \%$ difference between the daughter cells (35). While the ACD ratio was found to be $23 \%$ (ACD/total cell divisions: 20/86) in the control cells, it was $38 \%(33 / 88)$ in cells treated with BMP4 $(\mathrm{P}=0.004)$. Thus, BMP4 induced ACD in MGG8 cells (Fig. 4B). MKLP1 level with or without BMP4 treatment were compared using western blotting. In this experiment, the expression of MKLP1 under BMP4 treatment was not affected (Fig. 4C).

BMP4 signal suppressing sphere-forming ability in $M G G 8$ cells. Finally, whether BMP4 treatment affects self-renewal division in MGG8 cells was evaluated using the sphere assay. After a 3-day of BMP4 treatment, the large spheres of $>50 \mu \mathrm{m}$ in diameter were counted (Fig. 5A and B). Interestingly, those treated with BMP4 showed significantly low number of spheres as compared with control (Fig. 5A and B). This finding strongly suggests that BMP4 can suppress the self-renewal capability (symmetric cell division) of MGG8 cells.

\section{Discussion}

BMP4 has been shown to suppress CD133 expression and reduce the number of CD133-positive cells in GSCs (MGG8 cells). Furthermore, the mechanism underlying the CD133 inhibitory effects of BMP4 in GSCs mainly focused on cell division in this study. Cells at late telophase/cytokinesis showed the proportion of asymmetric division, and those with asymmetrically distributed CD133 increased with BMP4 treatment. These results indicate that the number of CD133-positive cells is suppressed with BMP4 treatment in GSCs.

BMP4 can inhibit cell proliferation and induce the expression of neural differentiation markers without affecting cell viability $(29,31)$. BMP4 also promotes cell differentiation in
GSCs both in vitro and in vivo $(29,31)$. Therefore, BMP4 and its signaling pathway, Smad pathway, can strongly be promising targets for differentiation therapy (31). Moreover, in our in vitro studies, BMP4 reduced the CD133-positive cell ratio in GSCs and its sphere-forming ability. Therefore, BMP4 treatment may improve the chemotherapeutic effects. BMP4 expression is downregulated in GBM as compared to normal brain in human samples (28), suggesting that this downregulation may cause drug resistance. BMP4 reverses drug resistance, such as temozolomide, by regulating the B-cell lymphoma 2(BCL-2) and glial cell-derived neurotrophic factor (39). Thus, BMP4 may act as an important inhibitory regulator of glioma tumorigenesis to improve the therapeutic efficacy combined with conventional chemotherapy and radiation therapy $(31,39,40)$.

Several studies have reported that CD133-positive GBM cells can effectively form tumors $(36,37,41)$. Studies have also been conducted to characterize the isolated cell population, using an anti-CD133 antibody as a specific cell surface marker to isolate CSCs (42). However, the antibodies routinely used as cell surface markers for CD133 target poorly specific glycoprotein epitopes, and skeptical arguments exist in using CD133 as a cell surface marker for CSCs (26). Recently, studies have been focusing on the functional analysis of CD133 itself. The phosphorylation of tyrosine-828 residue in CD133 C-terminal cytoplasmic domain results in the activation of PI3K/Akt pathway, which promotes GSC self-renewal and tumorigenesis (43). Furthermore, the role of CD133 in maintaining the undifferentiated state of cancer cells has recently been reported by inhibiting autophagy. That is, when CD133 is not phosphorylated by Src, CD133 is preferentially transported to the centrosome through the intracellular transport, and trap GABARAP, resulting in autophagy inhibition (44). These 
findings not only facilitate understanding the functional role of CD133 itself but also suggest the CD133 and its regulatory mechanisms as attractive therapeutic targets.

CSCs balance self-renewal and multipotency using the $\mathrm{ACD} / \mathrm{SCD}$ proportion and adapt to various environments. $\mathrm{ACD} / \mathrm{SCD}$ proportion is deeply involved in the maintenance of stemness of tumor tissue and proliferation of cancer cells $(32,33,45)$. Researchers believe that as CSCs become more malignant, they become more likely to divide symmetrically. Since SCD produces both two daughter CSCs, SCD leads to effectively the expansion of the CSC population $(33,45-48)$. The concept of ACD therapy, which suppresses CSCs symmetrical division and inhibits CSCs expansion, may establish a new strategy for cancer treatment.

Loss of function of the tumor suppressor gene TP53 has been shown to promote stemness maintenance (49). A recent study using a mammary cancer model that used PKH fluorescent dye labeling for stem cell mitotic analysis, showed that loss of p53 activity can induce a shift from ACD to SCD, thereby contributing to tumor growth (46). This study assumes that PKH-high cells have the greater stemness and the higher tumorigenic potential. In GBM, TRIM3 expression also attenuates the stemness of GSCs. In fact, TRIM3 expression suppresses both sphere formation and expression of stem cell markers such as CD133, Nestin, and Nanog. TRIM3 expression leads to a larger proportion of ACD rather than SCD (47). These studies assume that PKH-high cell have the greater stemness and the higher tumorigenic potential $(46,47)$. However, mitotic analysis using the PKH staining is not accompanied with analysis of cancer stem cell markers. On the other hand, we examined the mode of cell division using CD133, one of the most common markers of GSCs, and provided more direct evidence that BMP4 induces to ACD and suppresses self-renewal ability.

Although our study have been limited to in vitro experiments and have not clarified the effects of BMP4 in vivo, recent study shows that BMP4 reduces tumorigenic potential through the suppression of proliferation and the differentiation of GSCs (31). Therefore, our research approach may be also useful for further in vivo study. In conclusion, BMP4 induces ACD and suppresses self-renewal ability. This finding may provide a new perspective on how BMP4 reduces the tumorigenicity of GSCs.

\section{Acknowledgements}

This paper was presented at The 24th Annual Scientific Meeting and Education Day of The Society for NeuroOncology November 22-24, 2019, Phoenix, Arizona. The authors would like to thank Dr Hiroaki Wakimoto (Massahcusetts General Hospital) for the gift of glioma cells. The authors would also like to thank Mrs. Yumiko Oishi, Mrs. Chieko Mizukawa and Mrs. Akiko Soejima (Department of Neurosurgery, Faculty of Medicine, Saga University) for their secretarial assistance.

\section{Funding}

The present study was supported by JSPS KAKENHI (grant no. JP18K16589).

\section{Availability of data and materials}

All data generated or analyzed during the present study are included in this published article.

\section{Authors' contributions}

MK and HIz designed experiments. MK and $\mathrm{HIz}$ performed experiments. MK, YN, HIt, TW, FY, AO, KI, JM, HIz and TA analyzed the results. MK and HIz wrote the manuscript. MK, NY, HIz and TA conceived and supervised the project.

\section{Ethics approval and consent to participate}

Not applicable.

\section{Patient consent for publication}

Not applicable.

\section{Competing interests}

The authors declare that they have no competing interests.

\section{References}

1. Stupp R, Mason WP, van den Bent MJ, Weller M, Fisher B, Taphoorn MJ, Belanger K, Brandes AA, Marosi C, Bogdahn U, et al: Radiotherapy plus concomitant and adjuvant temozolomide for glioblastoma. NEngl J Med 352: 987-996, 2005.

2. Stupp R, Hegi ME, Mason WP, van den Bent MJ, Taphoorn MJ, Janzer RC, Ludwin SK, Allgeier A, Fisher B, Belanger K, et al: Effects of radiotherapy with concomitant and adjuvant temozolomide versus radiotherapy alone on survival in glioblastoma in a randomised phase III study: 5-year analysis of the EORTC-NCIC trial. Lancet Oncol 10: 459-466, 2009.

3. Rasras S, Zibara K, Vosughi T and Zayeri ZD: Genetics and epigenetics of glioblastoma: Therapeutic challenges. Clin Cancer Invest J 7: 43-49, 2018.

4. Deris Zayeri Z, Tahmasebi Birgani M, Mohammadi Asl J, Kashipazha D and Hajjari M: A novel infram deletion in MSH6 gene in glioma: Conversation on MSH6 mutations in brain tumors. J Cell Physiol 234: 11092-11102, 2019.

5. Antoniou A, Hébrant A, Dom G, Dumont JE and Maenhaut C: Cancer stem cells, a fuzzy evolving concept: A cell population or a cell property? Cell Cycle 12: 3743-3748, 2013.

6. Dalerba P, Cho RW and Clarke MF: Cancer stem cells: Models and concepts. Annu Rev Med 58: 267-284, 2007.

7. Wang T, Shigdar S, Gantier MP, Hou Y, Wang L, Li Y, Shamaileh HA, Yin W, Zhou SF, Zhao X and Duan W: Cancer stem cell targeted therapy: Progress amid controversies. Oncotarget 6: 44191-44206, 2015.

8. Soeda A, Hara A, Kunisada T, Yoshimura S, Iwama T and Park DM: The evidence of glioblastoma heterogeneity. Sci Rep 5: 7979, 2015.

9. Singh SK, Hawkins C, Clarke ID, Squire JA, Bayani J, Hide T, Henkelman RM, Cusimano MD and Dirks PB: Identification of human brain tumour initiating cells. Nature 432: 396-401, 2004.

10. Sampetrean O and Saya H: Characteristics of glioma stem cells. Brain Tumor Pathol 30: 209-214, 2013.

11. Bao S, Wu Q, McLendon RE, Hao Y, Shi Q, Hjelmeland AB, Dewhirst MW, Bigner DD and Rich JN: Glioma stem cells promote radioresistance by preferential activation of the DNA damage response. Nature 444: 756-760, 2006.

12. Bleau AM, Hambardzumyan D, Ozawa T, Fomchenko EI, Huse JT, Brennan CW and Holland EC: PTEN/PI3K/Akt pathway regulates the side population phenotype and $\mathrm{ABCG} 2$ activity in glioma tumor stem-like cells. Cell Stem Cell 4: 226-235, 2009.

13. Cheng L, Bao S and Rich JN: Potential therapeutic implications of cancer stem cells in glioblastoma. Biochem Pharmacol 80: 654-665, 2010. 
14. Sunayama J, Sato A, Matsuda K, Tachibana K, Watanabe E, Seino S, Suzuki K, Narita Y, Shibui S, Sakurada K, et al: FoxO3a functions as a key integrator of cellular signals that control glioblastoma stem-like cell differentiation and tumorigenicity. Stem Cells 29: 1327-1337, 2011.

15. Sato A, Sunayama J, Okada M, Watanabe E, Seino S, Shibuya K, Suzuki K, Narita Y, Shibui S, Kayama T and Kitanaka C: Gliomainitiating cell elimination by metformin activation of FOXO3 via AMPK. Stem Cells Transl Med 1: 811-824, 2012.

16. Bidlingmaier $S$, Zhu X and Liu B: The utility and limitations of glycosylated human CD133 epitopes in defining cancer stem cells. J Mol Med (Berl) 86: 1025-1032, 2008.

17. Singh SK, Clarke ID, Terasaki M, Bonn VE, Hawkins C, Squire J and Dirks PB: Identification of a cancer stem cell in human brain tumors. Cancer Res 63: 5821-5828, 2003.

18. Bao S, Wu Q, Li Z, Sathornsumetee S, Wang H, McLendon RE, Hjelmeland AB and Rich JN: Targeting cancer stem cells through L1CAM suppresses glioma growth. Cancer Res 68: 6043-6048, 2008.

19. Dreesen O and Brivanlou AH: Signaling pathways in cancer and embryonic stem cells. Stem Cell Rev 3: 7-17, 2007.

20. Eyler CE, Foo WC, LaFiura KM, McLendon RE, Hjelmeland AB and Rich JN: Brain cancer stem cells display preferential sensitivity to Akt inhibition. Stem Cells 26: 3027-3036, 2008.

21. Gallia GL, Tyler BM, Hann CL, Siu IM, Giranda VL, Vescovi AL, Brem H and Riggins GJ: Inhibition of Akt inhibits growth of glioblastoma and glioblastoma stem-like cells. Mol Cancer Ther 8: 386-393, 2009.

22. Fan X, Khaki L, Zhu TS, Soules ME, Talsma CE, Gul N, Koh C, Zhang J, Li YM, Maciaczyk J, et al: NOTCH pathway blockade depletes CD133-positive glioblastoma cells and inhibits growth of tumor neurospheres and xenografts. Stem Cells 28: 5-16, 2010

23. Xiao YT, Xiang LX and Shao JZ: Bone morphogenetic protein. Biochem Biophys Res Commun 362: 550-553, 2007.

24. Xiao L, Michalski N, Kronander E, Gjoni E, Genoud C, Knott G and Schneggenburger R: BMP signaling specifies the development of a large and fast CNS synapse. Nat Neurosci 16: 856-864, 2013.

25. Lim DA, Tramontin AD, Trevejo JM, Herrera DG, GarcíaVerdugo JM and Alvarez-Buylla A: Noggin antagonizes BMP signaling to create a niche for adult neurogenesis. Neuron 28 : 713-726, 2000

26. Johnston MA and Lim DA: Keeping them quiet: BMPs maintain adult neural stem cell quiescence. Cell Stem Cell 7: 9-10, 2010

27. Qi X, Li TG, Hao J, Hu J, Wang J, Simmons H, Miura S, Mishina Y and Zhao GQ: BMP4 supports self-renewal of embryonic stem cells by inhibiting mitogen-activated protein kinase pathways. Proc Natl Acad Sci USA 101: 6027-6032, 2004.

28. Xi G, Best B, Mania-Farnell B, James CD and Tomita T: Therapeutic potential for bone morphogenetic protein 4 in human malignant glioma. Neoplasia 19: 261-270, 2017.

29. Lee J, Son MJ, Woolard K, Donin NM, Li A, Cheng CH Kotliarova S, Kotliarov Y, Walling J, Ahn S, et al: Epigeneticmediated dysfunction of the bone morphogenetic protein pathway inhibits differentiation of glioblastoma-initiating cells. Cancer Cell 13: 69-80, 2008

30. Bonaguidi MA: LIF and BMP signaling generate separate and discrete types of GFAP-expressing cells. Development 132 . 5503-5514, 2005

31. Piccirillo SG, Reynolds BA, Zanetti N, Lamorte G, Binda E, Broggi G, Brem H, Olivi A, Dimeco F and Vescovi AL: Bone morphogenetic proteins inhibit the tumorigenic potential of human brain tumour-initiating cells. Nature 444: 761-765, 2006.

32. Morrison SJ and Kimble J: Asymmetric and symmetric stemcell divisions in development and cancer. Nature 441: 1068-1074 2006.

33. Bajaj J, Zimdahl B and Reya T: Fearful symmetry: Subversion of asymmetric division in cancer development and progression. Cancer Res 75: 792-797, 2015.
34. Wakimoto H, Mohapatra G, Kanai R, Curry WT Jr, Yip S, Nitta M, Patel AP, Barnard ZR, Stemmer-Rachamimov AO, Louis DN, et al: Maintenance of primary tumor phenotype and genotype in glioblastoma stem cells. Neuro Oncol 14: 132-144, 2012.

35. Lathia JD, Hitomi M, Gallagher J, Gadani SP, Adkins J, Vasanji A, Liu L, Eyler CE, Heddleston JM, Wu Q, et al: Distribution of CD133 reveals glioma stem cells self-renew through symmetric and asymmetric cell divisions. Cell Death Dis 2: e200, 2011.

36. Beier D, Hau P, Proescholdt M, Lohmeier A, Wischhusen J, Oefner PJ, Aigner L, Brawanski A, Bogdahn U and Beier CP: CD133(+) and CD133(-) glioblastoma-derived cancer stem cells show differential growth characteristics and molecular profiles. Cancer Res 67: 4010-4015, 2007.

37. Joo KM, Kim SY, Jin X, Song SY, Kong DS, Lee JI, Jeon JW, Kim MH, Kang BG, Jung Y, et al: Clinical and biological implications of CD133-positive and CD133-negative cells in glioblastomas. Lab Invest 88: 808-815, 2008.

38. Makyio H, Ohgi M, Takei T, Takahashi S, Takatsu H, Katoh Y, Hanai A, Ueda T, Kanaho Y, Xie Y, et al: Structural basis for Arf6-MKLP1 complex formation on the Flemming body responsible for cytokinesis. EMBO J 31: 2590-2603, 2012.

39. Liu B, Chen Q, Tian D, Wu L, Dong H, Wang J, Ji B, Zhu X, Cai Q, Wang L and Zhang S: BMP4 reverses multidrug resistance through modulation of BCL-2 and GDNF in glioblastoma. Brain Res 1507: 115-124, 2013.

40. Rahman M, Azari H, Deleyrolle L, Millette S, Zeng H and Reynolds BA: Controlling tumor invasion: Bevacizumab and BMP4 for glioblastoma. Future Oncol 9: 1389-1396, 2013.

41. Wang J, Sakariassen PØ, Tsinkalovsky O, Immervoll H, Bøe SO, Svendsen A, Prestegarden L, Røsland G, Thorsen F, Stuhr L, et al: CD133 negative glioma cells form tumors in nude rats and give rise to CD133 positive cells. Int J Cancer 122: 761-768, 2008.

42. Wei Y, Jiang Y, Zou F, Liu Y, Wang S, Xu N, Xu W, Cui C, Xing Y, Liu Y, et al: Activation of PI3K/Akt pathway by CD133p85 interaction promotes tumorigenic capacity of glioma stem cells. Proc Natl Acad Sci USA 110: 6829-6834, 2013.

43. Li Z: CD133: A stem cell biomarker and beyond. Exp Hematol Oncol 2: 17, 2013.

44. Izumi H, Li Y, Shibaki M, Mori D, Yasunami M, Sato S, Matsunaga H, Mae T, Kodama K, Kamijo T, et al: Recycling endosomal CD133 functions as an inhibitor of autophagy at the pericentrosomal region. Sci Rep 9: 2236, 2019.

45. Neumüller RA and Knoblich JA: Dividing cellular asymmetry: Asymmetric cell division and its implications for stem cells and cancer. Genes Dev 23: 2675-2699, 2009.

46. Cicalese A, Bonizzi G, Pasi CE, Faretta M, Ronzoni S, Giulini B, Brisken C, Minucci S, Di Fiore PP and Pelicci PG: The tumor suppressor $\mathrm{p} 53$ regulates polarity of self-renewing divisions in mammary stem cells. Cell 138: 1083-1095, 2009.

47. Chen G, Kong J, Tucker-Burden C, Anand M, Rong Y, Rahman F, Moreno CS, Van Meir EG, Hadjipanayis CG and Brat DJ: Human Brat ortholog TRIM3 is a tumor suppressor that regulates asymmetric cell division in glioblastoma. Cancer Res 74: 4536-4548, 2014.

48. Tominaga K, Minato H, Murayama T, Sasahara A, Nishimura T, Kiyokawa E, Kanauchi H, Shimizu S, Sato A, Nishioka K, et al: Semaphorin signaling via MICAL3 induces symmetric cell division to expand breast cancer stem-like cells. Proc Natl Acad Sci USA 116: 625-630, 2019.

49. Spike BT and Wahl GM: p53, Stem cells, and reprogramming: Tumor suppression beyond guarding the genome. Genes Cancer 2: 404-419, 2011.

This work is licensed under a Creative Commons Attribution-NonCommercial-NoDerivatives 4.0 International (CC BY-NC-ND 4.0) License. 